\begin{tabular}{|c|cc|}
\hline PORT SAID ENGINEERING RESEARCH JOURNAL \\
Faculty of Engineering - Port Said University \\
No. 1 \\
(Civil Engineering)
\end{tabular}

\title{
Using PPP-GNSS Technique for Detecting Surface Motion due to Earthquake Shaking based on time-domain analysis
}

\author{
Rasha Mosad ', Ashraf El-kutb², Ahmed El-Hattab', Mostafa Rabah ${ }^{4}$ and, Ashraf El-Koshy
}

Received: 14 July 2020; Accepted: 24 August 2020

\begin{abstract}
Many earthquakes with moderate magnitude have occurred in many areas of the world. The common procedures to extract the dynamic responses mainly depend on monitoring the change of the points in a time interval. This method could not be used to fully extract all dynamic parameters accompanied by the earthquake. To overcome these defects, and to analyze the seismic wave of those earthquakes, the GNSS precise point positioning (PPP) can be an effective tool for getting the values of the displacement of the point more accurate up to millimeters. In this paper, we apply the PPP technique to evaluate the station's displacement components and the station's heights in three different periods from the earthquake, Canadian Spatial Reference System Precise Point Positioning (CSRS-PPP) is used here [1]. Bernese GNSS 5.2 software is used as a reference to evaluate the PPP results [2]. Finally, it was found that PPP is an important tool for obtaining a high accuracy of our needed observations.
\end{abstract}

Keywords:_Precise Point Position, GNSS, Precise Orbit, point displacement, IGS Service.

\section{INTRODUCTION}

PPP is a positioning technique that removes or models GNSS system errors to provide a high level of position accuracy from a single receiver, A PPP solution depends on GNSS satellite clock and orbit corrections, once the corrections are calculated, they are delivered to the endusers via satellite.

These corrections are used by the receive resulting in decimeter-level, or better positioning with no base station required.PPP delivers accuracy up to 3 centimeters. A typical PPP solution requires time to converge to decimeter accuracy to resolve any local biases such as the atmospheric conditions, multipath environment, and satellite geometry. The actual accuracy achieved and the convergence time required depends on the quality of the corrections and how they are applied in the receiver but the main error sources for PPP which affect its accuracy are the ionospheric delay, the satellite orbit, and clock corrections, the tropospheric delay, and carrier-phase ambiguities.

${ }^{1}$ Civil Engineering Department, Faculty of Engineering, Port-said University, Egypt, corresponding author, email:rashamosaad@gmail.com

${ }^{2}$ Geodynamics Department, National Research Institute of Astronomy and Geophysics, Helwan, Cairo. email:Ashrafmousa07@gmail.com

${ }^{3}$ Civil Engineering Department, Faculty of Engineering, Port-said University, port said, Egypt, email:dr.ahmed.elhattab@gmail.com ${ }^{4}$ Civil Engineering Department, Faculty of Engineering, Banha University, Egypt, email:_mostafa_rabah@eng.psu.edu.eg

${ }^{5}$ Civil Engineering Department, Faculty of Engineering, Port-said University, Egypt,E-mail: dr.aelkoushy@gmail.com

DOI : $10.21608 /$ pserj.2020.35670.1052
It seems clear that PPP constitutes a major step forward in the development of high accuracy positioning, so this paper involved a study of using the PPP technique to reach a high accuracy of the station's network displacements according to the earthquake shaking, we extract the values of the movements of the points in three dimensional $\mathrm{X}, \mathrm{Y}, \mathrm{Z}$ are extracted. The data used here are a network data from the IGS (International GPS Service) [3].

\section{PROCESS OF THE AEGEAN EARTHQUAKES DATA USING BERNESE 5.2 SOFTWARE}

On 21 July 2017, a strong earthquake of magnitude of 6.6 occurred in the Aegean Sea, Turkey. The earthquake strike about $10 \mathrm{~km}(6.2 \mathrm{mi})$ south southeast of Bodrum, Turkey, at depth of $7.0 \mathrm{~km}$. The earthquake's epicenter was located just southwest of the small island of Kara Ada, on the northern side of the Gulf of Gökova,[6]. Which is a small Turkish island at the entrance of the harbor of Bodrum at the Aegean Sea? This earthquake is the focus of the current paper, Figure (1).

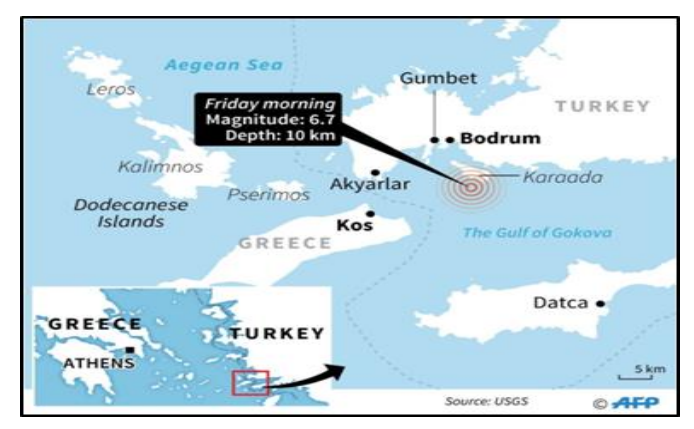

Figure 1:The epicenter of the Aegean earthquake 
Time-domain analysis is used here as an effective tool for earthquake prediction. The processing is made on three different times, to be able to extract as accurate data as possible, The analyzed time are; the first day of an earthquake that occurs $21 / 7 / 2017$, the second time in one week before at $14 / 7 / 2017$, third time is one week after the earthquake 28/7/2017. All needed data from IGS service, such as the GPS week, day of the week, day of the year, orbit data (Orbit file), Raw data for all points (Rinex file), the station's coordinates, Atmosphere file, and the ionosphere file

PPP requires a global network of GNSS reference stations to estimate precise satellite orbit and clock parameters in real-time, these parameters are transmitted to users, who can compute their position with an accuracy of $0.1 \mathrm{~m}$ using code and carrier observations. the main disadvantage of PPP takes a long time to converge to this accuracy, about 30-45 minutes. By Bernese GNSS software program version 5.2, our collected data of the Aegean network stations have been processed for each day we want to monitor the earthquake separately, and extract the required results in the ADDNEQ file that contains the outputs, tables $(1,2)$

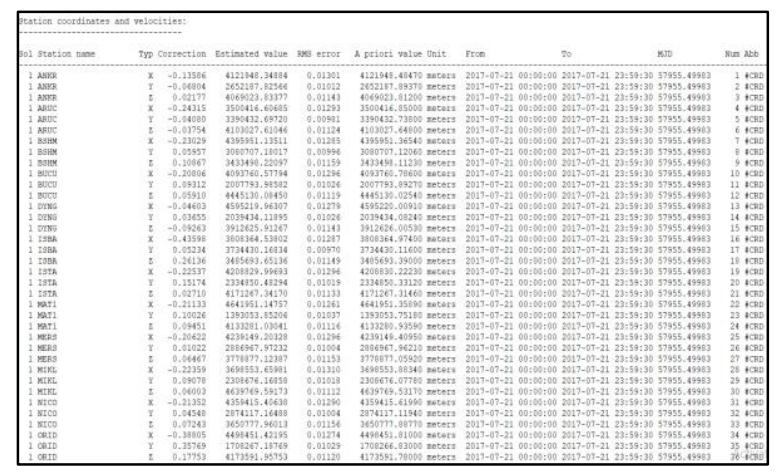

Table 1: Part of the output Addneq file showing the station coordinates and RMS error values.

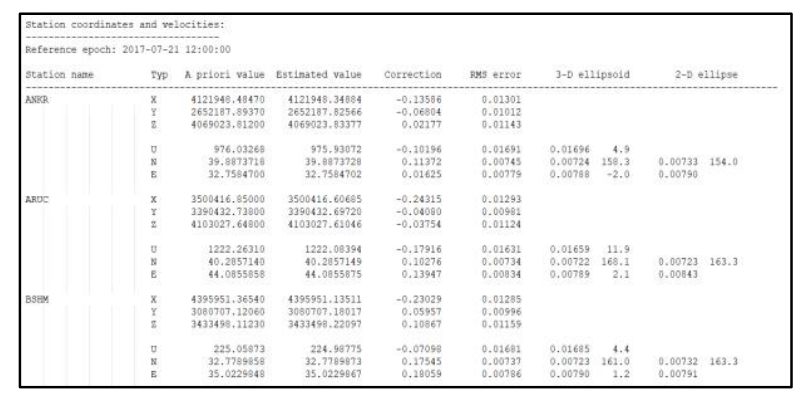

Table 2: Example of Stations Coordinates in two types of coordinates system $X, Y, Z$, and $U, N, V$.

After we get the estimated coordinates for each station and the error value in each one we can know the station's displacements in all directions $\mathrm{X}, \mathrm{Y}, \mathrm{Z}$ by subtracting the a priori coordinate from the estimated coordinates for each point on the three different dates. Tables $(3,4$, and 5).

\begin{tabular}{|c|c|c|}
\hline & & Day 21-7-2017 \\
\hline 41 & $X 2$ & $d X 1(\mathrm{~m})$ \\
\hline 4595219.96307 & 4359415.40638 & 235804.55669 \\
4595219.96307 & 4239149.20328 & 356070.75979 \\
\hline 4239149.20328 & 4359415.40638 & 120266.20310 \\
\hline 4359415.40638 & 4121948.34884 & 237467.05754 \\
\hline 4595219.96307 & 4121948.34884 & 473271.61423 \\
\hline 4595219.96307 & 4208829.99693 & 386389.96614 \\
\hline 4595219.96307 & 4498451.42195 & 96768.54112 \\
\hline 4595219.96307 & 3698553.65981 & 896666.30326 \\
\hline 4641951.14757 & 4595219.96307 & 46731.18450 \\
\hline 4641951.14757 & 3698553.65981 & 943397.48776 \\
\hline 4359415.40638 & 3808364.53802 & 551050.86836 \\
\hline 4395951.13511 & 4359415.40638 & 36535.72873 \\
\hline 4121948.34884 & 3500416.60685 & 621531.74199 \\
\hline 3808364.53802 & 3500416.60685 & 307947.93117 \\
\hline 4595219.96307 & 4395951.13511 & 199268.82796 \\
\hline
\end{tabular}

Table 3: $\mathrm{X}$ coordinate for the baselines network on the day of the earthquake.

\begin{tabular}{|c|c|c|c|c|}
\hline \multicolumn{3}{|c|}{ Aegean Sea-Earthqauke -Turky } & \multicolumn{2}{|c|}{ the day before $14-7$} \\
\hline station1 & station2 & $\mathrm{x}_{1}$ & $x_{2}$ & $d X 2(m)$ \\
\hline DYNG & NICO & 4595220.08403 & 4359415.53318 & 235804.55085 \\
\hline DYNG & MERS & 4595220.08403 & no data & no data \\
\hline MERS & NICO & no data & 4359415.53318 & no data \\
\hline NICO & ANKR & 4359415.53318 & 4121948.46664 & 237467.06654 \\
\hline DYNG & ANKR & 4595220.08403 & 4121948.46664 & 473271.61739 \\
\hline DYNG & ISTA & 4595220.08403 & 4208830.11909 & 386389.96494 \\
\hline DYNG & ORID & 4595220.08403 & 4498451.54271 & 96768.54132 \\
\hline DYNG & MIKL & 4595220.08403 & 3698553.77461 & 896666.30942 \\
\hline MAT1 & DYNG & 4641951.25943 & 4595220.08403 & 46731.17540 \\
\hline MAT1 & MIKL & 4641951.25943 & 3698553.77461 & 943397.48482 \\
\hline NICO & ISBA & 4359415.53318 & 3808364.65438 & 551050.87880 \\
\hline BSHM & NICO & 4395951.24856 & 4359415.53318 & 36535.71538 \\
\hline ANKR & ARUC & 4121948.46664 & 3500416.72025 & 621531.74639 \\
\hline ISBA & ARUC & 3808364.65438 & 3500416.72025 & 307947.93413 \\
\hline DYNG & BSHM & 4595220.08403 & 4395951.24856 & 199268.83547 \\
\hline
\end{tabular}

Table 4: $X$ coordinate for the baselines network on a week before the earthquake.

\begin{tabular}{|c|c|c|}
\hline & & After 28-7-2017 \\
\hline $\mathbf{x 1}$ & $\mathbf{x} 2$ & dX3 (m) \\
\hline 4595220.01173 & 4359415.46265 & 235804.54908 \\
\hline 4595220.01173 & 4239149.26264 & 356070.74909 \\
\hline 4239149.26264 & 4359415.46265 & 120266.20001 \\
\hline 4359415.46265 & 4121948.39849 & 237467.06416 \\
\hline 4595220.01173 & 4121948.39849 & 473271.61324 \\
\hline 4595220.01173 & 4208830.05050 & 386389.96123 \\
\hline 4595220.01173 & 4498451.50160 & 96768.51013 \\
\hline 4595220.01173 & 3698553.70386 & 896666.30787 \\
\hline 4641951.20065 & 4595220.01173 & 46731.18892 \\
\hline 4641951.20065 & 3698553.70386 & 943397.49679 \\
\hline 4359415.46265 & 3808364.58276 & 551050.87989 \\
\hline 4395951.18193 & 4359415.46265 & 36535.71928 \\
\hline 4121948.39849 & 3500416.65806 & 621531.74043 \\
\hline 3808364.58276 & 3500416.65806 & 307947.92470 \\
\hline 4595220.01173 & 4395951.18193 & 199268.82980 \\
\hline
\end{tabular}

Table5: $X$ coordinates for the baselines network on a week after the earthquake.

Likewise, both $\mathrm{Y}$ and $\mathrm{Z}$ coordinates are tabulated for each monitored date of the earthquake. It is noticeable that there is no available data for MERS station for day $14 / 7 / 2017$ because there was no raw data for that date in the IGS service, it may be due to the maintenance work of the station or a change of the receiver. Figures (2, 3, and 4) are examples of the changes of baseline stations $\mathrm{X}$ coordinates component's for one baseline (DYNGNICO) on different three times of the Aegean earthquake.

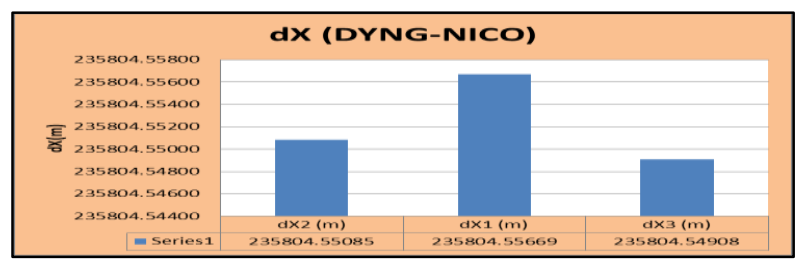

Figure 2: The dX values of baseline (DYNG-NICO)

Figure (2) shows that $\mathrm{dX} 2$ on a week before the earthquake is lower than $\mathrm{dx} 1$ on the day of the 
earthquake with about $5 \mathrm{~mm}$, dx1value increased, and then decreased on the week after the earthquake with about $7 \mathrm{~mm}$ this indicates that the ground surface will go to the normal statue.

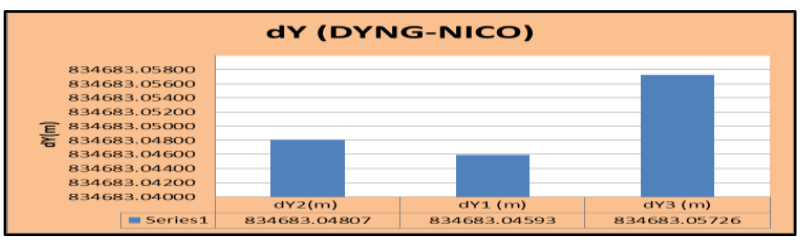

Figure 3: The dY values of baseline (DYNG-NICO)

In figure (3), we found that dY2 increased on the day before the earthquake about $3 \mathrm{~mm}$, then on the day after one week from shaking dY3 increased about $1 \mathrm{~cm}$ than the day of the earthquake, it may happen because the forces of the earthquake were still affecting the earth surface due to the nature of the earth in this region, or maybe another earthquake will occur soon.

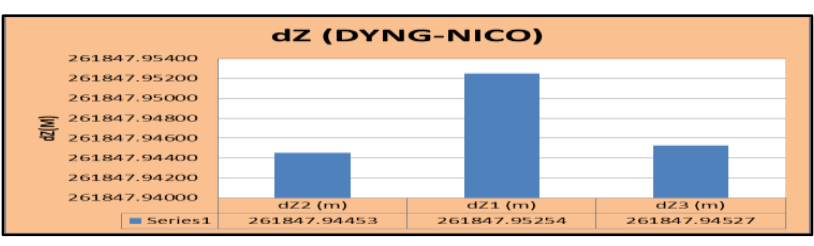

Figure 4: The dZ values of baseline (DYNG-NICO)

We found in figure (4) that $\mathrm{dZ}$ increased on the day of the earthquake more than before and after the earthquake's shock ended, we noticed that $\mathrm{dZ}$ decreased again and began to reach stability.

\section{THE DISPLACEMENTS COMPONENTS OF THE NETWORK BASELINES LENGTH'S}

In this step, we calculated the displacements values for all network baselines which are joint between two stations,(Table 6). dX2, dY2, dZ2 are taken as a reference to get other values, it means $\Delta \mathrm{dX} 1=(\mathrm{dX} 2$ $\mathrm{dX} 1) \mathrm{m}, \Delta \mathrm{dX} 3=(\mathrm{dX} 2-\mathrm{dX} 3) \mathrm{m}$ and so on the other values of $\Delta \mathrm{dY} 1, \Delta \mathrm{dY} 3, \Delta \mathrm{dZ} 1, \Delta \mathrm{dZ} 3$.according to the result sign (+ or-)we can know if this baseline increased its length or decreased, so we can know the movements of both baseline end.

Table ': Meter Values of $\Delta d x, \Delta d Y, \& \Delta d Z$ of Baselines Network

\begin{tabular}{|c|c|c|c|c|c|c|}
\hline \multicolumn{7}{|c|}{ The Estimated $\triangle d X, Y, Z$} \\
\hline Baselines & $\Delta d X 1 \mathrm{~m}$ & $\Delta d X 3 \mathrm{~m}$ & $\Delta d \mathrm{Y} 1 \mathrm{~m}$ & $\triangle d Y 3 m$ & $\Delta d Z 1 \mathrm{~m}$ & $\triangle d Z 3 \mathrm{~m}$ \\
\hline bsselinel & -0.00584 & 0.00177 & 0.00214 & 0.00919 & 0.008001 & -0.00074 \\
\hline bsseline2 & no data & no data & nodata & nodata & no data & no data \\
\hline baseline3 & no datta & no data & nodata & no data & nodatt & no data \\
\hline baselinet & 0.00900 & 0.00238 & 0.00683 & 0.00060 & -0.01560 & -0.00745 \\
\hline baseline5 & 0.00316 & 0.00415 & 0.00469 & 0.00979 & 0.00759 & -0.00611 \\
\hline baseline6 & -0.00120 & 0.00371 & 0.00102 & -0.00119 & 0.00458 & -0.0330 \\
\hline baseline? & 0.00020 & 0.00975 & 0.00078 & 0.01531 & 0.00493 & -0.01176 \\
\hline baseline8 & 0.00616 & 0.00155 & 0.00562 & -0.01415 & -0.01573 & -0.01701 \\
\hline bsselines & -0.00910 & 0.01352 & 0.00148 & 0.00561 & -0.00319 & -0.0519 \\
\hline basseline10 & -0.00294 & -0.01197 & -0.00710 & 0.00854 & 0.01254 & -0.01182 \\
\hline basslinel1 & 0.01044 & 0.00109 & 0.01216 & 0.00512 & 0.01225 & 0.00735 \\
\hline baseline12 & -0.01335 & -0.00390 & -0.01026 & 0.00210 & 0.01527 & 0.00705 \\
\hline baselinel3 & 0.00440 & 0.00596 & 0.00892 & 0.01144 & 0.00318 & -0.01123 \\
\hline baselinel4 & 0.00296 & 0.00943 & 0.00359 & 0.00692 & -0.00583 & -0.01133 \\
\hline baseline15 & 0.00751 & 0.00567 & 0.00812 & 0.01129 & 0.00726 & 0.00631 \\
\hline
\end{tabular}

From the Table 6, we noticed that there is no data for baseline numbers 2 and 3. Because there was not any available raw data of MERS station on the date of $14 / 7 / 2017$ on the day before one week from the earthquake. It maybe happened because of any maintenance work or change the receiver which takes many days that the station stops working.

Baseline number1 (DYNG-NICO), it is noticed that its length of the first baseline increased by $5 \mathrm{~mm}$, whereby $\Delta \mathrm{dX} 1=-0.005(5 \mathrm{~mm})$, and $\Delta \mathrm{dX} 1=(\mathrm{dX} 2-\mathrm{dX} 1) \mathrm{m}$. On the day after a week, $\Delta \mathrm{dX} 3$ is decreased $1 \mathrm{~mm}$ only. It may be an indication that the effect of shaking that happened on the day of the earthquake was more than normal and that the stations started to go to their stability after one week from the earthquake shaking.

In $\mathrm{Y}$ direction we found that $\Delta \mathrm{dY} 1$ decreased $2 \mathrm{~mm}$, but after a week the length increased $9 \mathrm{~mm}$. It means that the stations were still affected by the earthquake forces under the ground surface. And it may be a sign of occurring an earthquake as soon on that region. As each of both stations are close to the epicenter of the earthquake and the Aegean sea. In $\mathrm{Z}$ direction, it is found the value of $\Delta \mathrm{dZ} 1=-0.008 \mathrm{~m}$, So the baseline length has increased $8 \mathrm{~mm}$, but on the day after a week from the earthquake, the value $\Delta \mathrm{dZ3}=0 .-0007 \mathrm{~m}$, which means that the length increased also only $1 \mathrm{~mm}$.

The resulted displacements are arranged in tables 7and 8 , for the day of the earthquake and the day after one week from the earthquake.

Table7: Estimated Displacements on the day of the earthquake.

\begin{tabular}{|llll|}
\hline The Baselines & $\Delta \mathrm{dXI}$ & $\Delta \mathrm{dYI}$ & $\Delta \mathrm{dZ1}$ \\
DYNG-NICO & $5 \mathrm{~mm}$ & $2 \mathrm{~mm}$ & $8 \mathrm{~mm}$ \\
NICO-ANKR & $9 \mathrm{~mm}$ & $7 \mathrm{~mm}$ & $1 \mathrm{~cm}$ \\
DYNG-ANKR & $3 \mathrm{~mm}$ & $5 \mathrm{~mm}$ & $7 \mathrm{~mm}$ \\
DYNG-ISTA & $1 \mathrm{~mm}$ & $1 \mathrm{~mm}$ & $4 \mathrm{~mm}$ \\
DYNG-ORID & $1 \mathrm{~mm}$ & $1 \mathrm{~mm}$ & $4 \mathrm{~mm}$ \\
DYNG-MIKL & $6 \mathrm{~mm}$ & $5 \mathrm{~mm}$ & $1 \mathrm{~cm}$ \\
MAT1-DYNG & $9 \mathrm{~mm}$ & $1 \mathrm{~mm}$ & $3 \mathrm{~mm}$ \\
MAT1-MIKL & $2 \mathrm{~mm}$ & $7 \mathrm{~mm}$ & $1 \mathrm{~cm}$ \\
NICO-ISBA & $1 \mathrm{~cm}$ & $1 \mathrm{~cm}$ & $1 \mathrm{~cm}$ \\
BSHM-NICO & $1 \mathrm{~cm}$ & $1 \mathrm{~cm}$ & $1 \mathrm{~cm}$ \\
ANKR-ARUC & $4 \mathrm{~mm}$ & $8 \mathrm{~mm}$ & $3 \mathrm{~mm}$ \\
ISBA-ARUC & $2 \mathrm{~mm}$ & $3 \mathrm{~mm}$ & $5 \mathrm{~mm}$ \\
DYNG-BSHM & $7 \mathrm{~mm}$ & $8 \mathrm{~mm}$ & $7 \mathrm{~mm}$ \\
\hline
\end{tabular}

In table 7 , it is noticed that many baselines have displacement value reached to $1 \mathrm{~cm}$, like (NICOANKR), (NICO-ISBA) and (BSHM-NICO), Because of NICO station is considered the nearest stations to the epicenter. So it is affected greatly. The station ISBA in the baseline (NICO-ISBA), is one of the most distant stations in the network from the epicenter. But maybe its topography and the nature of its ground surface make it vulnerable to the earthquake shaking. Or maybe its surface keeps the earthquake forces for a longer period. All of the above reasons may be led to big displacement values. Also, the baseline (NICO- BSHM) has big displacements values in all directions; the reason for that is both stations are closed to the epicenter, and their geographical location makes their baselines near the sea coast. So it is has affected clearly. The rest of the network baselines have also varying values of displacements, starting from $1 \mathrm{~mm}$ to $9 \mathrm{~mm}$, which 
depends on the distances between stations or baselines and the epicenter of the earthquake.

Table8: Estimated Displacements on the day after a week of the earthquake.

\begin{tabular}{|llll|}
\hline Baselines & $\Delta \mathrm{dX3}$ & $\Delta \mathrm{dY} 3$ & $\Delta \mathrm{dZ3}$ \\
DYNG-NICO & $1 \mathrm{~mm}$ & $9 \mathrm{~mm}$ & $1 \mathrm{~mm}$ \\
NICO-ANKR & $2 \mathrm{~mm}$ & $6 \mathrm{~mm}$ & $7 \mathrm{~mm}$ \\
DYNG-ANKR & $4 \mathrm{~mm}$ & $9 \mathrm{~mm}$ & $6 \mathrm{~mm}$ \\
DYNG-ISTA & $3 \mathrm{~mm}$ & $1 \mathrm{~mm}$ & $4 \mathrm{~mm}$ \\
DYNG-ORID & $9 \mathrm{~mm}$ & $1 \mathrm{~cm}$ & $1 \mathrm{~cm}$ \\
DYNG-MIKL & $1 \mathrm{~mm}$ & $1 \mathrm{~cm}$ & $1 \mathrm{~cm}$ \\
MATI-DYNG & $1 \mathrm{~cm}$ & $5 \mathrm{~mm}$ & $5 \mathrm{~mm}$ \\
MATI-MIKL & $1 \mathrm{~cm}$ & $8 \mathrm{~mm}$ & $1 \mathrm{~cm}$ \\
NICO-ISBA & $1 \mathrm{~mm}$ & $5 \mathrm{~mm}$ & $7 \mathrm{~mm}$ \\
BSHM-NICO & $3 \mathrm{~mm}$ & $2 \mathrm{~mm}$ & $7 \mathrm{~mm}$ \\
ANKR-ARUC & $5 \mathrm{~mm}$ & $1 \mathrm{~cm}$ & $1 \mathrm{~cm}$ \\
ISBA-ARUC & $9 \mathrm{~mm}$ & $6 \mathrm{~mm}$ & $1 \mathrm{~cm}$ \\
DYNG-BSHM & $5 \mathrm{~mm}$ & $1 \mathrm{~cm}$ & $6 \mathrm{~mm}$ \\
\hline
\end{tabular}

The displacement values on the day after the week of the earthquake are shown in table 8 , it is noticed that some baselines have normal movement values ranged from 1 $\mathrm{mm}$ to $2 \mathrm{~mm}$ but there are big values as well. An example of these baselines is the baseline (DYNGANKR), which has values of $4 \mathrm{~mm}$ to $9 \mathrm{~mm}$, this is maybe due to the very close distance between stations and the epicenter. Baselines (DYNG-ORID) and (DYNG-MIKL) have values of $9 \mathrm{~mm}, 1 \mathrm{~cm}$, and $1 \mathrm{cmand}$ $1 \mathrm{~mm}, 1 \mathrm{~cm}, 1 \mathrm{~cm}$ respectively. Because stations are close to the epicenter. The displacement values are evidence of any change in the Earth's crust. These changes may be attributed to the surface layer of the earth's crust is weak in this region, which leads to a large movement of these stations. On the other hand, it may indicate an early warning of any natural disaster close to this area such as an earthquake or a volcano. But to ensure that it requires daily monitoring of the Earth's crust in such areas to facilitate earthquake prediction. other values are between $3 \mathrm{~mm}$ to $9 \mathrm{~mm}$ as a maximum

\section{STATIONS DISPLACEMENTS USING THE PRECISE POINT POSITIONS (PPP) TECHNIQUE}

Precise Point Positioning (PPP) is a technique used to determine the position of the receiver antenna without communication with the reference station, using a single global navigation satellite system (GNSS) receiver. PPP uses carrier phase observations as the principal observable for position determination which capable of providing very high positioning accuracy. PPP needs accurate satellite orbit and clock information to mitigate orbit and clock errors. So the PPP solution depends on GNSS satellite orbit and clock corrections. The permanent services which execute calculations with PPP technique are: Automatic Precise Positioning Service (APPS), Canadian Spatial Reference System Precise Point Positioning (CSRS-PPP), GNSS Analysis and Positioning Software (GAPS) and magicPPP - Precise Point Positioning Solution (magic GNSS). In this paper we used the Canadian Spatial Reference System Precise Point Positioning (CSRS-PPP) for determining station coordinates, the static processing mode is used, the datum is ITRF 14, and the RINEX observation file of each station sends. A mail with a PPP file for each point was then received. Finally, stations with PPP coordinates with high accuracy on three different times are obtained, on the day of the earthquake on 21/7/2107, on a week before the earthquake at 14/7/2017, and a week after the earthquake at 28/7/2017.

Table 9: PPP Coordinates of the Network Baselines on the day of the Aegean Earthquake.

\begin{tabular}{|c|c|ccc|}
\hline \multicolumn{3}{|c}{ The PPP coordinates } & \multicolumn{2}{c|}{ Day 21/7/2017 } \\
station1 & station2 & X1 ppp & X2ppp & dX1ppp(m) \\
\hline DYNG & NICO & 4595220.03750 & 4359415.48170 & 235804.55580 \\
DYNG & MERS & 4595220.03750 & 4239149.28470 & 356070.75280 \\
MERS & NICO & 4239149.28470 & 4359415.48170 & 120266.19700 \\
NICO & ANKR & 4359415.48170 & 4121948.42230 & 237467.05940 \\
DYNG & ANKR & 4595220.03750 & 4121948.42230 & 473271.61520 \\
DYNG & ISTA & 4595220.03750 & 4208830.07240 & 386389.96510 \\
DYNG & ORID & 4595220.03750 & 4498451.49730 & 96768.54020 \\
DYNG & MIKL & 4595220.03750 & 3698553.73700 & 896666.30050 \\
MAT1 & DYNG & 4641951.22130 & 459522.003750 & 46731.18380 \\
MAT1 & MIKL & 4641951.22130 & 3698553.73700 & 943397.48430 \\
NICO & ISBA & 4359415.48170 & 3808364.61780 & 551050.86390 \\
BSHM & NICO & 4395951.21030 & 4359415.48170 & 36535.72860 \\
ANKR & ARUC & 4121948.42230 & 3500416.68080 & 621531.74150 \\
ISBA & ARUC & 3500416.68080 & 3808364.61780 & 307947.93700 \\
DYNG & BSHM & 4595220.03750 & 4395951.21030 & 199268.82720 \\
\hline
\end{tabular}

Table 10: PPP of Y Coordinates of the Network Baselines on the day of the Aegean Earthquake

\begin{tabular}{|c|c|c|}
\hline Y1ppp & Y2ppp & dY1ppp(m) \\
\hline 2039434.16030 & 2874117.20310 & 834683.04280 \\
\hline 2039434.16030 & 2886968.00620 & 847533.84590 \\
\hline 2886968.00620 & 2874117.20310 & 12850.80310 \\
\hline 2874117.20310 & 2652187.86800 & 221929.33510 \\
\hline 2039434.16030 & 2652187.86800 & 612753.70770 \\
\hline 2039434.16030 & 2334850.52550 & 295416.36520 \\
\hline 2039434.16030 & 1708267.23140 & 331166.92890 \\
\hline 2039434.16030 & 2308676.21020 & 269242.04990 \\
\hline 1393053.89860 & 2039434.16030 & 646380.26170 \\
\hline 1393053.89860 & 2308676.21020 & 915622.31160 \\
\hline 2874117.20310 & 3734430.20670 & 860313.00360 \\
\hline 3080707.21720 & 2874117.20310 & 206590.01410 \\
\hline 2652187.86800 & 3390432.73030 & 738244.86230 \\
\hline 3390432.73030 & 3734430.20670 & 343997.47640 \\
\hline 2039434.16030 & 3080707.21720 & 1041273.05690 \\
\hline
\end{tabular}

Table 11: PPP of $Z$ Coordinates of the Network Baselines on the day of the Aegean Earthquake

\begin{tabular}{|c|c|c|}
\hline Z1ppp & Z2ppp & dZ1ppp $(\mathrm{m})$ \\
\hline 3912625.93420 & 3650777.98420 & 261847.95000 \\
\hline 3912625.93420 & 37788877.14810 & 133748.78610 \\
\hline 3778877.14810 & 3650777.98420 & 128099.16390 \\
\hline 3650777.98420 & 4069023.85380 & 418245.86960 \\
3912625.93420 & 4069023.85380 & 156397.91960 \\
\hline 3912625.93420 & 4171267.36310 & 258641.42890 \\
\hline 3912625.93420 & 4173591.97790 & 260966.04370 \\
\hline 3912625.93420 & 4639769.61010 & 727143.67590 \\
\hline 4133281.04990 & 3912625.93420 & 220655.11570 \\
\hline 4133281.04990 & 4639769.61010 & 506488.56020 \\
\hline 3650777.98420 & 3485693.67790 & 165084.30630 \\
\hline 3433498.24460 & 3650777.98420 & 217279.73960 \\
\hline 4069023.85380 & 4103027.62940 & 34003.77560 \\
4103027.62940 & 3485693.67790 & 617333.95150 \\
\hline 3912625.93420 & 3433498.24460 & 479127.68960 \\
\hline
\end{tabular}

Likewise, the precise coordinates of all network stations on the day of the earthquake are extracted on tables $(9,10,11)$. It was repeated in the other two days before and after one week of the earthquake.

The sconed stage is computing the precise baseline displacements of the network. On the three different days from the earthquake as in tables 12,13 ,and14. 
Table 12: Calculations of $\Delta \mathrm{dX} 1 \mathrm{ppp}, \& \Delta \mathrm{dX} 3 \mathrm{ppp}$ Values

\begin{tabular}{|c|c|c|c|c|c|c|}
\hline station1 & station2 & dX1ppp(m) & $d X 2 p p p(m)$ & dX3 ppp(m) & $\Delta d X 1 p p p=(d x 2-d x 1) \mid m$ & $\Delta d X 3 p p p=[d x 2-d x 3) m$ \\
\hline DYNG & NICO & 235804.55580 & 235804.54980 & 235804.54270 & $\cdot 0.00600$ & 0.00710 \\
\hline DYNG & MERS & 356070.75280 & nodata & 356070.74200 & no data & nodata \\
\hline MERS & NICO & 120266.19700 & no data & 120266.19930 & no data & nodata \\
\hline NICO & ANKR & 237467.05940 & 237467.06450 & 237467.06220 & 0.00510 & 0.00230 \\
\hline DYNG & ANKR & 473271.61520 & 473271.61430 & 473271.60490 & -0.00090 & 0.00940 \\
\hline DYNG & ISTA & 386389.96510 & 386389.96070 & 386389.95540 & $\cdot 0.00440$ & 0.00530 \\
\hline DYNG & ORID & 96768.54020 & 96768.53450 & 96768.53160 & $\cdot 0.00570$ & 0.00290 \\
\hline DYNG & MIKL & 896666.30050 & 896666.30110 & 896666.29500 & 0.00060 & 0.00610 \\
\hline MAT1 & DYNG & 46731.18380 & 46731.17740 & 46731.18530 & .0 .00640 & .0 .00790 \\
\hline MAT1 & MIKL & 943397.48430 & 943397.47850 & 943397.48030 & $\cdot 0.00580$ & -0.00180 \\
\hline NICO & ISBA & 551050.86390 & 551050.86560 & 551050.87160 & 0.00170 & -0.00600 \\
\hline BSHM & NICO & 36535.72860 & 36535.72180 & 36535.71680 & -0.00680 & 0.00500 \\
\hline ANKR & ARUC & 621531.74150 & 621531.74080 & 621531.74000 & .0 .00070 & 0.00080 \\
\hline ISBA & ARUC & 307947.93700 & 307947.93970 & 307947.93060 & 0.00270 & 0.00910 \\
\hline DYNG & BSHM & 199268.82720 & 199268.82800 & 199268.82590 & 0.00080 & 0.00210 \\
\hline
\end{tabular}

Table 12 explains the values of $\Delta \mathrm{dX} 1$ on the day of the earthquake which $\Delta \mathrm{dX} 1=(\mathrm{dX} 2-\mathrm{dX} 1) \mathrm{m}$. Taken value of $\mathrm{dX} 2$ as reference. Likewise, computes the $\Delta \mathrm{dX} 3$ values of on a week after the earthquake, with $\Delta \mathrm{dX} 3=(\mathrm{dX} 2-$ dX3) $m$. From the tabled values we noticed that on the day of the earthquake the minimum value of length change was $1 \mathrm{~mm}$ and reached $6 \mathrm{~mm}$ as the maximum value. The stations near the epicenter of an earthquake have a big movement regardless of the result signal positive or negative, such as stations NICO, DYNG, ISTA, ANKAR, and MAT1, where the change value about $3 \mathrm{~mm}$ to $6 \mathrm{~mm}$. But the other far stations had fewer values about $1 \mathrm{~mm}$ as stations BSHM, MIKL, and ARUC.

A week after an earthquake, it was noticed that the values of $\Delta \mathrm{dX} 3 \mathrm{ppp}$ are clearly increased on all the nearest baselines from the epicenter such as (DYNGNICO) had a value of $7 \mathrm{~mm}$, (DYNG $-\mathrm{ANKR})=9 \mathrm{~mm}$, ( DYNG $-\mathrm{MIKL})=6 \mathrm{~mm}$, These changes mean that the baseline with stations closer to the center suffering huge displacement. Even if the baseline was connected between two stations, one was far, but the other station was very close to the center of the earthquake that produced also a significant change in the location of the point on the earth's crust. Thus, the station location is the main factor that affects the magnitude of its displacement when the earthquake occurs.

Table13: Calculations of $\Delta d y 1 p p p, \& \Delta d y 3 p p p$ Values

\begin{tabular}{|c|c|c|c|c|c|c|}
\hline station1 & station2 & $d Y 1 p p p(m)$ & $d K 2 p p p(m)$ & $d Y 3 p p p(m)$ & $\Delta d Y 1 p p p=|d y 2-d y 1| \mathrm{m}$ & $\Delta d Y 3 p p p=(d y 2-d y 3 \mid m$ \\
\hline DYNG & NICO & 834683.04280 & 834683.04410 & 834683.05180 & 0.00130 & -0.00770 \\
\hline DYNG & MERS & 847533.84590 & no data & 8475333.86030 & nodata & nodata \\
\hline MERS & NICO & 12850.80310 & nodata & 12850.80850 & nodata & no data \\
\hline NICO & ANKR & 221929.33510 & 221929.33930 & 221929.34170 & 0.00420 & -0.00240 \\
\hline DYNG & ANKR & 612753.70770 & 612753.70480 & 612753.71010 & -0.00290 & -0.00530 \\
\hline DYNG & ISTA & 295416.36520 & 295416.36310 & 295416.36760 & -0.00210 & -0.00450 \\
\hline DYNG & ORID & 331166.92890 & 331166.92750 & 331166.92430 & -0.00140 & 0.00320 \\
\hline DYNG & MIKL & 269242.04990 & 269242.04650 & 269242.05560 & -0.00340 & -0.00910 \\
\hline MAT1 & DYNG & 646380.26170 & 646380.26550 & 646380.26000 & 0.00380 & 0.00550 \\
\hline MAT1 & MIKL. & 915622.31160 & 915622.31200 & 915622.31560 & 0.00040 & -0.00360 \\
\hline NICO & ISBA & 860313.00360 & 860313.00340 & 860312.99770 & $\cdot 0.00020$ & 0.00570 \\
\hline BSHM & NICO & 206590.01410 & 206590.01060 & 206590,00450 & -0.00350 & 0.00610 \\
\hline ANKR & ARUC & 738244.86230 & 738244.86230 & 738244.86760 & 0.00000 & -0.00530 \\
\hline ISBA & ARUC & 343997,47640 & 343997.48040 & 343997.47180 & 0.00400 & 0.00860 \\
\hline DYNG & BSHM & 1041273.05690 & 1041273.05470 & 1041273.05630 & -0.00220 & -0.00160 \\
\hline
\end{tabular}

Table14: Calculations of $\Delta \mathrm{dZ1} 1 \mathrm{ppp}, \& \Delta \mathrm{dZ3} p \mathrm{pp}$ Values

\begin{tabular}{|c|c|c|c|c|c|c|}
\hline station1 & station2 & dz1.1ppp $(\mathrm{m})$ & $d 22 p p p(m)$ & d23ppp $(\mathrm{m})$ & $\Delta d z 1 p p p=(d 22 \cdot d 21) \mathrm{m}$ & $\Delta d 23 p p p=\mid 22 \cdot d 23] \mathrm{m}$ \\
\hline DYNG & NICO & 261847.95000 & 261847.94690 & 261847.94200 & $\cdot 0.00310$ & 0.00490 \\
\hline DYNG & MERS & 133748.78610 & no data & 133748.77290 & nodata & nodata \\
\hline MERS & NICO & 128099.16390 & nodata & 128099.16910 & nodata & nodata \\
\hline NICO & ANKR & 418245.86960 & 418245.86370 & 418245.86640 & -0.00590 & $\cdot 0.00270$ \\
\hline DYNG & ANKR & 156397.91960 & 156397.91680 & 156397.92440 & $\cdot 0.00280$ & $\cdot 0.00760$ \\
\hline DYNG & ISTA & 258641.42890 & 258641.42860 & 258641.43260 & $\cdot 0.00030$ & $\cdot 0.00400$ \\
\hline DYNG & ORID & 260966.04370 & 260966.04460 & 260966.05000 & 0.00090 & $\cdot 0.00540$ \\
\hline DYNG & MIKL & 727143.67590 & 727143.67240 & 727143.68540 & $\cdot 0.00350$ & $\cdot 0.01300$ \\
\hline MAT1 & DYNG & 220655.11570 & 220655.11350 & 220655.11560 & $\cdot 0.00220$ & $\cdot 0.00210$ \\
\hline MAT1 & MIKL & 506488.56020 & 506488.55890 & 506488.56980 & $\cdot 0.00130$ & $\cdot 0.01090$ \\
\hline NICO & ISBA & 165084,30630 & 165084,30890 & 165084,31100 & 0.00260 & $\cdot 0.00210$ \\
\hline BSHM & NCCO & 217279.73960 & 217279.74890 & 217279.74800 & 0.00930 & 0.00090 \\
\hline ANKR & ARUC & 34003.77560 & 34003.77690 & 34003.78060 & 0.00130 & $\cdot 0.00370$ \\
\hline ISBA & ARUC & 617333.95150 & 617333.94950 & 617333.95800 & $\cdot 0.00200$ & $\cdot 0.00850$ \\
\hline DYNG & BSHM & 479127.68960 & 479127.69580 & 479127,69000 & 0.00620 & 0.00580 \\
\hline
\end{tabular}

The same previous scenario has been done on the rest values of the displacements in $\mathrm{Y}$ and $\mathrm{Z}$ directions which are evident from the previous tables 13 and 14 . The most important note is that the closer the station to the epicenter of the earthquake, the greater the change in the Earth's crust, therefore the more points displacements from their fixed location on the earth's crust, and vice versa also the more the station moves away from the epicenter of the earthquake, the less the change in the Earth's crust, so the less the displacement of points.

Now, these results will be presented in a graphic relationship in figures $(5,6$, and 7$)$. They show the difference between point displacements for each baseline of the network surrounding the epicenter of the earthquake.

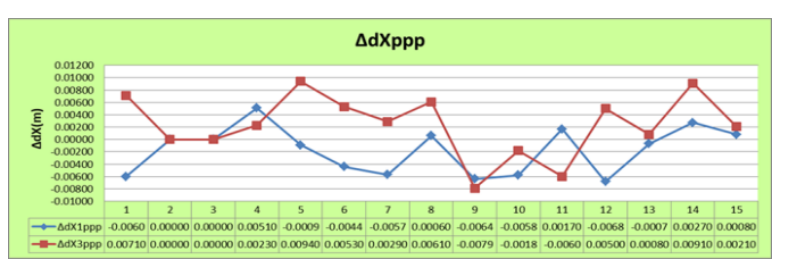

Figure 5: $\triangle \mathrm{dX1PPP}$ Values for the Network Baselines

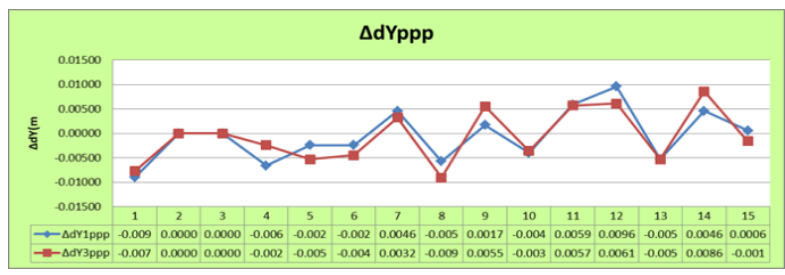

Figure 6: $\triangle$ dY1PPP Values for the Network Baselines

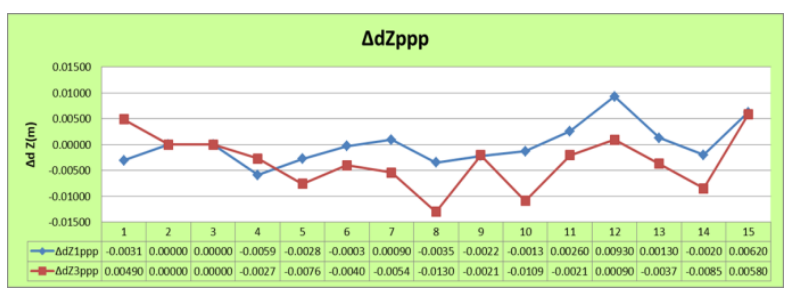

Figure 7: $\triangle$ dZ1PPP Values for the Network Baselines 
The precise displacement values are shown in the previous curves. So the difference of station displacement values according to the time domain have been noticed.

\section{FIND THE HEIGHT CHANGE OF STATIONS USING THE PRECISE POSITION TECHNIQUE}

Among the factors that have been monitored to know the point displacement is $\mathrm{dH}$. The calculation of the height displacement of the network stations according to the output file from Bernese 5.2 software. We should make a reference data guide contains all parameters that are affected when earthquakes occur. To serve our community and protect it from the earthquake's danger and create an effective earthquake prediction tool soon.

Table15: The Output of Stations Heights from Bernese Processing Software

\begin{tabular}{|c|c|c|c|c|}
\hline \multicolumn{4}{|l|}{$21 / 7 / 2017$} & \\
\hline station 1 & station2 & $h 1(m)$ & h2(m) & $\operatorname{dh} 1(\mathrm{~m})$ \\
\hline DYNG & NiCO & 510.48986 & 189.92874 & 320.56112 \\
\hline DYNG & MERS & 510.48986 & 38.48829 & 472.00157 \\
\hline MERS & NICO & 189.92874 & 38.3816 & 151.54714 \\
\hline NICO & ANKR & 975.93072 & 189.92874 & 786.00198 \\
\hline DYNG & ANKR & 975.93072 & 510.48986 & 465.44086 \\
\hline DYNG & ISTA & 510.48986 & 147.16701 & 363.32285 \\
\hline DYNG & ORID & 772.93157 & 510.48986 & 262.44171 \\
\hline DYNG & MIKL & 510.48986 & 93.85211 & 416.63775 \\
\hline MAT1 & DYNG & 534.4531 & 510.48986 & 23.96324 \\
\hline MAT1 & MIKL & 534.54922 & 93.85211 & 440.69711 \\
\hline NICO & ISBA & 189.92874 & 72.28833 & 117.64041 \\
\hline BSHM & NICO & 224.98775 & 189.92874 & 35.05901 \\
\hline ANKR & ARUC & 1222.08394 & 975.93072 & 246.15322 \\
\hline ISBA & ARUC & 1222.08394 & 72.28833 & 1149.79561 \\
\hline DYNG & BSHM & 510.48986 & 224.98775 & 285.50211 \\
\hline
\end{tabular}

Table 16: PPP Stations height using the Canadian Spatial Reference System (CSRS-PPP).

\begin{tabular}{|c|c|c|c|c|}
\hline $\begin{array}{c}21 / 7 / 2017 \\
\text { station1 }\end{array}$ & station2 & h1ppp(m) & h2ppp(m) & dh1ppp(m) \\
DYNG & NICO & 510.56990 & 190.01120 & 320.55870 \\
DYNG & MERS & 510.56990 & 38.46540 & 472.10450 \\
MERS & NICO & 38.46540 & 190.01120 & 151.54580 \\
NICO & ANKR & 190.01120 & 976.00860 & 785.99740 \\
DYNG & ANKR & 510.56990 & 976.00860 & 465.43870 \\
DYNG & ISTA & 510.56990 & 147.24630 & 363.32360 \\
DYNG & ORID & 510.56990 & 773.00970 & 262.43980 \\
DYNG & MIKL & 510.56990 & 93.92520 & 416.64470 \\
MAT1 & DYNG & 534.52950 & 510.56990 & 23.95960 \\
MAT1 & MIKL & 534.52950 & 93.92520 & 440.60430 \\
NICO & ISBA & 190.01120 & 72.37290 & 117.63830 \\
BSHM & NICO & 225.07020 & 190.01120 & 35.05900 \\
ANKR & ARUC & 976.00860 & 1222.15430 & 246.14570 \\
ISBA & ARUC & 72.37290 & 1222.15430 & 1149.78140 \\
DYNG & BSHM & 510.56990 & 225.07020 & 285.49970 \\
\hline
\end{tabular}

Tables 15 and 16 display the point's height values in the two solutions on the day of the earthquake. Then calculate the difference heights between every two stations of the baseline, which $(\mathrm{dh}=\mathrm{h} 1-\mathrm{h} 2)$. We will repeat the same steps to find the height difference dh on the other two days from the earthquake. The first day is on 14/7/2017, before one week, and the day of 28/7/2017 after one week from the earthquake.
Table17: Station's Heights Displacements using Bernese solution

\begin{tabular}{|c|c|c|c|c|c|c|}
\hline station1 & station2 & dh2 (m) & dh1 $(m)$ & $\mathrm{dh} 3(\mathrm{~m})$ & $\Delta \mathrm{dh} 1=(\mathrm{dh} 2-\mathrm{dh} 1) \mathrm{m}$ & $\Delta \mathrm{dh} 3=(\mathrm{dh} 2-\mathrm{dh} 3) \mathrm{m}$ \\
\hline DYNG & NICO & 320.55290 & 320.56112 & 320.54196 & -0.00822 & 0.01094 \\
\hline DYNG & MERS & no data & 472.00157 & 472.08771 & no data & no data \\
\hline MERS & NICO & no data & 151.54714 & 151.54575 & no data & no data \\
\hline NICO & ANKR & 785.97973 & 786.00198 & 785.98269 & -0.02225 & -0.00296 \\
\hline DYNG & ANKR & 465.42683 & 465.44086 & 465.44073 & -0.01403 & -0.01390 \\
\hline DYNG & ISTA & 363.32940 & 363.32285 & 363.32341 & 0.00655 & 0.00599 \\
\hline DYNG & ORID & 262.43613 & 262.44171 & 262.52006 & -0.00558 & -0.08393 \\
\hline DYNG & MIKL & 416.66732 & 416.63775 & 416.64922 & 0.02957 & 0.01810 \\
\hline MAT1 & DYNG & 23.95341 & 23.96324 & 23.96448 & -0.00983 & -0.01107 \\
\hline МАт1 & MIKL & 440.62073 & 440.69711 & 440.61370 & -0.07638 & 0.00703 \\
\hline NICO & ISBA & 117.66807 & 117.64041 & 117.65239 & 0.02766 & 0.01568 \\
\hline BSHM & NICO & 35.03722 & 35.05901 & 35.04767 & -0.02179 & -0.01045 \\
\hline ANKR & ARUC & 246.13587 & 246.15322 & 246.15944 & -0.01735 & -0.02357 \\
\hline ISBA & ARUC & 1149.78367 & 1149.79561 & 1149.79452 & -0.01194 & -0.01085 \\
\hline WNG & BSHM & 285.51568 & 285.50211 & 285.49429 & 0.01357 & 0.02139 \\
\hline
\end{tabular}

Table18: Calculation Values of $\Delta$ dh1PPPand $\Delta \mathrm{dh} 3$ PPP

\begin{tabular}{|c|c|c|c|c|c|c|}
\hline station1 & station2 & dh2ppp(m) & dh1ppp(m) & dh3ppp(m) & $\Delta d h 1 p p p=(d h 2-d h 1) m$ & Ddh3ppp=(dh2-dh3)m \\
\hline DYNG & NICO & 320.55200 & 320.55870 & 320.54110 & -0.00670 & 0.01090 \\
\hline DYNG & MERS & no data & 472.10450 & 472.08290 & no data & no data \\
\hline MERS & NICO & nodata & 151.54580 & 151.54180 & no data & na data \\
\hline NICO & ANKR & 785.98850 & 785.99740 & 785.99050 & -0.00890 & -0.00200 \\
\hline DYNG & ANKR & 465.43650 & 465.43870 & 465.44940 & -0.00220 & -0.01290 \\
\hline DYNG & ISTA & 363.32140 & 363.32360 & 363.31370 & -0.00220 & 0.00770 \\
\hline DYNG & ORID & 262.44480 & 262.43980 & 262.45140 & 0.00500 & -0.00660 \\
\hline DYNG & MIKL & 416.64830 & 416.64470 & 416.63220 & 0.00360 & 0.01610 \\
\hline MAT1 & DYNG & 23.95260 & 23.95960 & 23.96120 & -0.00700 & -0.00860 \\
\hline MAT1 & MIKL & 440.60090 & 440.60430 & 440.59340 & -0.00340 & 0.00750 \\
\hline NICO & ISBA & 117.64100 & 117.63830 & 117.67260 & 0.00270 & -0.03160 \\
\hline BSHM & NICO & 35.04750 & 35.05900 & 35.04180 & -0.01150 & 0.00570 \\
\hline ANKR & ARUC & 246.14690 & 246.14570 & 246.15200 & 0.00120 & -0.00510 \\
\hline ISBA & ARUC & 1149.77640 & 1149.78140 & 1149.79510 & -0.00500 & -0.01870 \\
\hline DYNG & BSHM & 285.50450 & 285.49970 & 285.49930 & 0.00480 & 0.00520 \\
\hline
\end{tabular}

From tables 17 and 18 , we can see a comparison between the station's height displacement values in the two solutions, it is found the baseline number 1 has $\Delta \mathrm{dh} 1=$ $8 \mathrm{~mm}$ as height difference in Bernese case and in PPP equal $6 \mathrm{~mm} \Delta$ dh1PPP. After one week from the earthquake $\Delta \mathrm{dh} 3=1 \mathrm{~cm}$ equal the value of $\Delta \mathrm{dh} 3 \mathrm{ppp}=1$ $\mathrm{cm}$. The day when an earthquake occurred the vertical estimated displacements were about 1 to $2 \mathrm{~cm}$ and also after one week the values were within nearly the same range.in PPP solution also there a lot of values have about this value range. So it should be continuous monitoring of points displacement to ensure the correctness of these displacements for each point. Taking into account all influencing factors such as the point location, the geographical location and the strength of the earthquake as well.

\section{DETERMINE THE PRECISE DISPLACEMENTS FOR THE NETWORK STATIONS}

The online service of The Canadian Geodetic Survey of Natural Resources (CSRS-PPP) is used to get the precise values. We have requested to get the results in the ITRF datum at an epoch other than the epoch of GNSS data. The solution is returned via an email at the address provided on the submission page and downloaded directly to a user. The CSRS-PPP outputs are the solution report (.pdf) presenting the PPP results in a combination of textual and graphical information, summary file (.sum) which contains the parameters and the results of the PPP processing, and A position file (.pos) containing the positioning information for each epoch processed. So each station of our network sends 
its name and its raw data and then have an email with its precise position. As shown in tables 20 and 21.

Table 20: Part of the summary file (.sum) which contains the parameters of the PPP processing

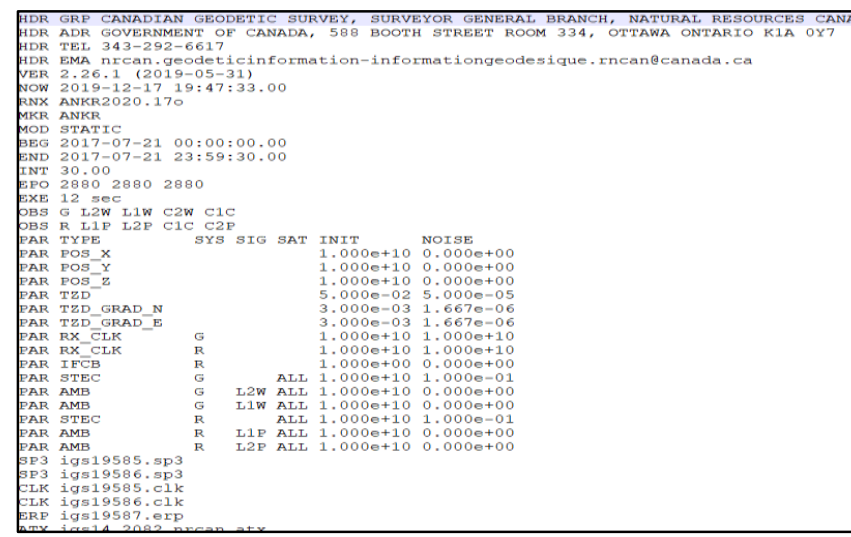

Table21: Part of the summary file contains the results of the PPP processing.

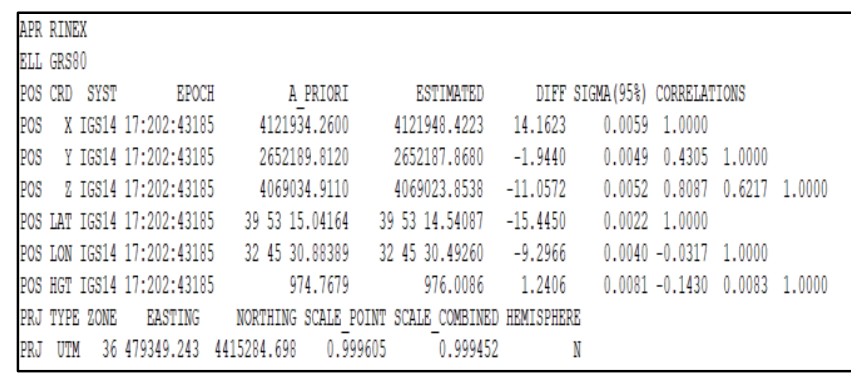

We will present the precise displacements of the network baselines in the directions $\mathrm{X}, \mathrm{Y}$, and $\mathrm{Z}$ (see tables 22,23,24). Then compare these results with the estimated displacements resulted by Bernese processing, table (26).

Table 22: Calculations of $\Delta \mathrm{dX1ppp,} \mathrm{\&} \Delta \mathrm{dX} 3 \mathrm{ppp}$ Values

\begin{tabular}{|c|c|c|c|c|c|c|}
\hline station1 & station2 & $\mathrm{dX1ppp(m)}$ & $d X 2 p p p(m)$ & $d X 3 \mathrm{ppp}(\mathrm{m})$ & $\Delta d X 1 p p p=(d \times 2-d \times 1) m$ & $\Delta d X 3 p p p=\mid d \times 2-d$ \\
\hline DYNG & NICO & 235804.55580 & 235804.54980 & 235804.54270 & -0.00600 & 0.00710 \\
\hline DYNG & MERS & 356070.75280 & no data & 356070.74200 & no data & no data \\
\hline MERS & NICO & 120266.19700 & no data & 120266.19930 & no data & no data \\
\hline NICO & ANKR & 237467.05940 & 237467.06450 & 237467.06220 & 0.00510 & 0.00230 \\
\hline DYNG & ANKR & 473271.61520 & 473271.61430 & 473271.60490 & -0.00090 & 0.00940 \\
\hline DYNG & ISTA & 386389.96510 & 386389.96070 & 386389.95540 & -0.00440 & 0.00530 \\
\hline DYNG & ORID & 96768.54020 & 96768.53450 & 96768.53160 & -0.00570 & 0.00290 \\
\hline DYNG & MIILL & 896666.30050 & 896666.30110 & 896666.29500 & 0.00060 & 0.00610 \\
\hline MAT1 & DYNG & 46731.18380 & 46731.17740 & 46731.18530 & -0.00640 & -0.00790 \\
\hline MAT1 & MIILL & 943397.48430 & 943397.47850 & 943397.48030 & -0.00580 & -0.00180 \\
\hline NICO & ISBA & 551050.86390 & 551050.86560 & 551050.87160 & 0.00170 & -0.00600 \\
\hline BSHM & NICO & 36535.72860 & 36535.72180 & 36535.71680 & -0.00680 & 0.00500 \\
\hline ANKR & ARUC & 621531.74150 & 621531.74080 & 621531.74000 & -0.00070 & 0.00080 \\
\hline ISBA & ARUC & 307947.93700 & 307947.93970 & 307947.93060 & 0.00270 & 0.00910 \\
\hline DYNG & BSHM & 199268.82720 & 199268.82800 & 199268.82590 & 0.00080 & 0.00210 \\
\hline
\end{tabular}

From table 22, the baseline displacements in $\mathrm{X}$ direction explain that the values on the day of the earthquake ranged between $1 \mathrm{~mm}$ to $6 \mathrm{~mm}$ as a maximum value. For the day after a week of the earthquake, the values of $\Delta \mathrm{dX} 3 \mathrm{ppp}$ clearly increased on all baselines near the epicenter. Evidently, DYNG-NICO had a value of $7 \mathrm{~mm}$; DYNG-ANKR $=9 \mathrm{~mm} ;$ DYNG-MIKL $=6 \mathrm{~mm} ;$ and DYNG- MAT1 $=8 \mathrm{~mm}$.
Table 23: Calculations of $\Delta d y 1 p p p, \& \Delta d y 3 p p p$ Values

\begin{tabular}{|c|c|c|c|c|c|c|}
\hline station1 & station2 & $d Y 1 p p p(m)$ & $d Y 2 p p p(m)$ & $d Y 3 p p p(m)$ & $\Delta d Y 1 p p p=|d y 2-d y 1| m$ & $\Delta d Y 3 p p p=|d \gamma| 2 d y 3 \mid n$ \\
\hline DYNG & NICO & 834683.04280 & 834683.04410 & 834683.05180 & 0.00130 & -0.00770 \\
\hline DYNG & MERS & 847533.84590 & nodate & 847533.86030 & no data & no date \\
\hline MERS & NICO & 12850.80310 & nodata & 12850.80850 & nodata & no data \\
\hline NICO & ANKR & 221929.33510 & 221929.33930 & 221929,34170 & 0.00420 & -0.00240 \\
\hline DYNG & ANKR & 612753.70770 & 612753.70480 & 612753.71010 & $\cdot 0.00290$ & $\cdot 0.00530$ \\
\hline DYNG & ISTA & 295416.36520 & 295416.36310 & 295416.36760 & -0.00210 & -0.00450 \\
\hline DYNG & ORID & 331166.92890 & 331166.92750 & 331166.92430 & $\cdot 0.00140$ & 0.00320 \\
\hline DYNG & MIKL & 269242.04990 & 269242.04650 & 269242.05560 & -0.00340 & -0.00910 \\
\hline MAT1 & DYNG & 646380.26170 & 646380.26550 & 646380.26000 & 0.00380 & 0.00550 \\
\hline MAT1 & MIKL & 915622.31160 & 915622.31200 & 915622.31560 & 0.00040 & -0.00360 \\
\hline NCO & ISBA & 860313.00360 & 860313.00340 & 860312.99770 & -0.00020 & 0.00570 \\
\hline BSHM & NICO & 206590,01410 & 206590.01060 & 206590.00450 & -0.00350 & 0.00610 \\
\hline ANKR & ARUC & 738244.86230 & 738244.86230 & 738244.86760 & 0.00000 & $\cdot 0.00530$ \\
\hline ISBA & ARUC & 343997.47640 & 343997,48040 & 343997,47180 & 0.00400 & 0.00860 \\
\hline DYNG & BSHM & 1041273.05690 & 1041273.05470 & 1041273.05630 & -0.00220 & -0.00160 \\
\hline
\end{tabular}

Table 24: Calculations of $\Delta \mathrm{dZ1} 1 \mathrm{ppp}, \& \Delta \mathrm{dZ3} p \mathrm{pp}$ Values

\begin{tabular}{|c|c|c|c|c|c|c|}
\hline station1 & station2 & d21.ppp $(m)$ & d22ppp $(\mathrm{m})$ & d23ppp/m) & $\Delta d z 1 p p p=(d 22-d 21) \mid \mathrm{m}$ & $\Delta d 23 p p p=[22-d 23 \mid \mathrm{m}$ \\
\hline DYNG & NCO & 261847,95000 & 261847,94690 & 261847,94200 & $\cdot 0.00310$ & 0.00490 \\
\hline DYNG & MERS & 133748.78610 & nodata & 133748.772290 & nodata & nodata \\
\hline MERS & NCO & 128099.16390 & nodata & 128099.16910 & nodata & nodata \\
\hline NICO & ANKR & 418245.86960 & 418245.86370 & 418245.86640 & -0.00590 & -0.00270 \\
\hline DYNG & ANKR & 156397,91960 & 156397,91680 & 156397.92440 & -0.00280 & $\cdot 0.00760$ \\
\hline DYNG & ISTA & 258641.42890 & 258641.42860 & 258641.43260 & -0.00030 & $\cdot 0.00400$ \\
\hline DYNG & ORID & 260966.04370 & 260966.04460 & 260966.05000 & 0.00090 & $\cdot 0.00540$ \\
\hline DYNG & MIKL. & 727143.67590 & 727143.67240 & 727143.68540 & -0.00350 & $\cdot 0.01300$ \\
\hline MAT1 & DYNG & 220655.11570 & 220655.11350 & 220655.11560 & -0.00220 & $\cdot 0.00210$ \\
\hline MAT1 & MIKL & 506488.56020 & 506488.55890 & 506488.569980 & -0.00130 & $\cdot 0.01090$ \\
\hline NCO & ISBA & 165084,30630 & 165084,30890 & 165084.31100 & 0.00260 & $\cdot 0.00210$ \\
\hline BSHM & NICO & 217279.73960 & 217279.74890 & 217279.74800 & 0.00930 & 0.00090 \\
\hline ANKR & ARUC & 34003.77560 & 34003.77690 & 34003.78060 & 0.00130 & $\cdot 0.00370$ \\
\hline ISBA & ARUC & 617333.95150 & 617333.94950 & 617333.95800 & -0.00200 & $\cdot 0.00850$ \\
\hline DYNG & BSHM & 479127.68960 & 479127.69580 & 479127.69000 & 0.00620 & 0.00580 \\
\hline
\end{tabular}

Tables 23 and 24 show the computed displacement values of $\Delta d Y 1 p p p, \Delta d Y 3 p p p, \Delta d Z 1 p p p$, and $\Delta d Z 3 p p p$. They imply that the displacements in the $\mathrm{Y}$ direction ranged from $1 \mathrm{~mm}$ to $7 \mathrm{~mm}$ and that in the $\mathrm{Z}$ direction the values were from $2 \mathrm{~mm}$ to $7 \mathrm{~mm}$, except for the two values of the baselines DYNG-MIKL and MAT1-MIKL that reached $1 \mathrm{~cm}$. Being the closest to the epicenter, the DYNG station hit the biggest displacement value.

\section{COMPARING THE BASELINES COORDINATES DISPLACEMENTS VALUES}

The baseline displacements values are tabled in tables 25 and26, to can extract any important notes and any differences between both solutions. 
Table 25: Displacement Values of $\Delta d X, \Delta d Y, \& \Delta d Z$ of all Network Baselines

\begin{tabular}{|c|c|c|c|c|c|c|}
\hline \multicolumn{7}{|c|}{ The Estimated $\Delta d X, Y, Z$} \\
\hline Baselines & $\Delta d X 1 m$ & $\Delta d X 3 \mathrm{~m}$ & $\Delta d Y 1 m$ & $\Delta d Y 3 m$ & $\Delta d Z 1 \mathrm{~m}$ & $\Delta d Z 3 m$ \\
\hline baseline1 & $\cdot 0.00584$ & 0.00177 & 0.00214 & -0.00919 & $\cdot 0.00801$ & -0.00074 \\
\hline baseline2 & nodata & nodata & nodata & nodata & nodata & nodata \\
\hline baseline3 & nodata & nodata & nodata & nodata & nodata & nodata \\
\hline baselinet & 0.00900 & 0.00238 & 0.00683 & 0.00060 & $\cdot 0.01560$ & -0.00745 \\
\hline baselines & 0.00316 & 0.00415 & $\cdot 0.00469$ & -0.00979 & -0.00759 & -0.00671 \\
\hline baseline6 & $\cdot 0.00120$ & 0.00371 & 0.00102 & -0.00119 & $\cdot 0.00458$ & -0.00390 \\
\hline baseline? & 0.00020 & 0.03119 & $\cdot 0.00078$ & 0.01531 & $\cdot 0.00993$ & -0.09176 \\
\hline baselines & 0.00616 & 0.00155 & $\cdot 0.00562$ & -0.01415 & $\cdot 0.01573$ & -0.01701 \\
\hline baselineg & $\cdot 0.00910$ & $\cdot 0.01352$ & $\cdot 0.00148$ & 0.00561 & $\cdot 0.00319$ & -0.00519 \\
\hline baseline10 & .0 .00294 & $\cdot 0.01197$ & $\cdot 0.00710$ & -0.00854 & -0.01254 & -0.01182 \\
\hline baselinel1 & 0.01044 & .0 .00109 & $\cdot 0.01216$ & -0.00512 & 0.01295 & 0.00735 \\
\hline baseline12 & $\cdot 0.01335$ & $\cdot 0.00390$ & $\cdot 0.01026$ & -0.00210 & 0.01527 & 0.00705 \\
\hline baseline13 & 0.00440 & 0.0596 & $\cdot 0.00892$ & -0.01144 & $\cdot 0.00318$ & -0.01123 \\
\hline baseline14 & 0.00296 & 0.00943 & 0.00359 & 0.00692 & $\cdot 0.00583$ & -0.01133 \\
\hline baseline15 & 0.00751 & 0.00567 & $\cdot 0.00812$ & -0.01129 & 0.00726 & 0.00631 \\
\hline
\end{tabular}

Table 26: Precise Displacement Values of $\Delta d X p p p$,

$\Delta d Y p p p, \& \Delta d Z p p p$ of all Network Baselines

\begin{tabular}{|c|c|c|c|c|c|c|}
\hline \multicolumn{2}{|c|}{ The ppp $\Delta d X, Y, Z$} & \multirow[b]{2}{*}{$\Delta d X 3 p p p m$} & \multirow[b]{2}{*}{ ddY1ppp m } & \multirow[b]{2}{*}{$\Delta d Y 3 p p p m$} & \multirow[b]{2}{*}{ Adz1ppp m } & \multirow[b]{2}{*}{$\Delta d 23 p p p m$} \\
\hline Baselines & adXIppp m & & & & & \\
\hline baselinel & -0.00600 & 0.00710 & 0.00130 & -0.00770 & $\cdot 0,00310$ & 0.00490 \\
\hline baseline? & no data & no data & no data & nodata & nodata & no data \\
\hline baseline3 & no data & nodata & no data & nodata & no data & nodata \\
\hline baseline4 & 0.00510 & 0.00230 & 0.00420 & -0.00240 & $\cdot 0,00590$ & $\cdot 0.00270$ \\
\hline baseline5 & $\cdot 0.00090$ & 0.00940 & -0.00290 & $\cdot 0.00530$ & $\cdot 0.00280$ & $\cdot 0.00760$ \\
\hline baseline6 & $\cdot 0.00440$ & 0.00530 & $-0,00210$ & -0.00450 & -0.00030 & $\cdot 0,00400$ \\
\hline baseline? & $\cdot 0.00570$ & 0.00290 & -0.00140 & 0.00320 & 0.00090 & $\cdot 0,00540$ \\
\hline baseline8 & 0.00060 & 0.00610 & -0.00340 & -0.00910 & -0.00350 & $\cdot 0.01300$ \\
\hline baselineg & $\cdot 0.00640$ & -0.00790 & 0.00380 & 0.00550 & $\cdot 0,00220$ & $\cdot 0.00210$ \\
\hline baseline10 & $\cdot 0.00580$ & -0.00180 & 0.00040 & -0.00360 & $\cdot 0.00130$ & $\cdot 0.01090$ \\
\hline baseline11 & 0.00170 & -0.00600 & -0.00020 & 0.00570 & 0.00260 & $-0,00210$ \\
\hline baseline12 & $\cdot 0,00680$ & 0.00500 & $-0,00350$ & 0.00610 & 0.00930 & 0.00090 \\
\hline baseline13 & $\cdot 0.00070$ & 0.00080 & 0.00000 & -0.00530 & 0.00130 & $\cdot 0.00370$ \\
\hline baseline14 & 0.00270 & 0.00910 & 0.00400 & 0.00860 & -0.00200 & $\cdot 0.00850$ \\
\hline baseline15 & 0.00080 & 0.00210 & -0.00220 & $-0,00160$ & 0.00620 & 0.00580 \\
\hline
\end{tabular}

When the absolute meter values of $\Delta \mathrm{dX} 1$ and $\Delta \mathrm{dX} 1 \mathrm{ppp}$ on the day of the earthquake are compared, it becomes clear that the highest values are close to one another in two cases. For example, the estimated displacement value and the PPP value of baseline 1 are correspondingly equal. It is noticed that the difference between the estimated displacement values and the PPP displacement values on the day of the earthquake ranges from $3 \mathrm{~mm}$ to $5 \mathrm{~mm}$.

As for the displacement values of $\Delta \mathrm{dX} 3$ and $\Delta \mathrm{dX} 3 p p p$ on the day after a week of the earthquake, the difference between the Bernese solution and the PPP solution at most stations ranges from $2 \mathrm{~mm}$ to $6 \mathrm{~mm}$. Yet, the baseline MAT1-MIKL hits the displacement value of $1 \mathrm{~cm}$, but it is only $1 \mathrm{~mm}$ in the PPP. On the other hand, baseline DYNG-ORID records $3 \mathrm{~cm}$ in the Bernese solution while it is $3 \mathrm{~mm}$ in the PPP solution. This indicates that an evident change occurs in the coordinates of these two solutions.

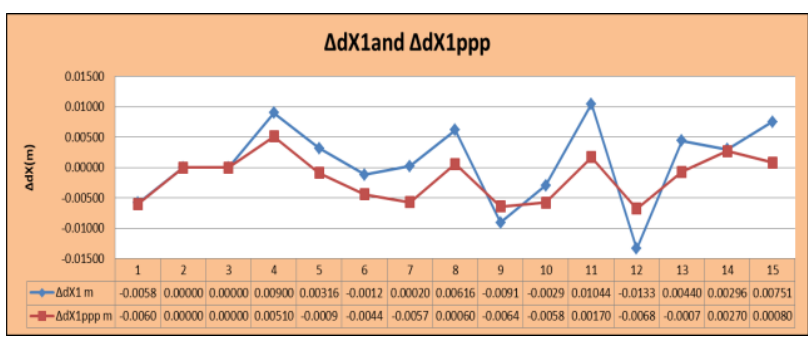

Figure ': Graph of the Difference Between $\Delta d X 1 \&$ $\triangle d X 1$ PPP

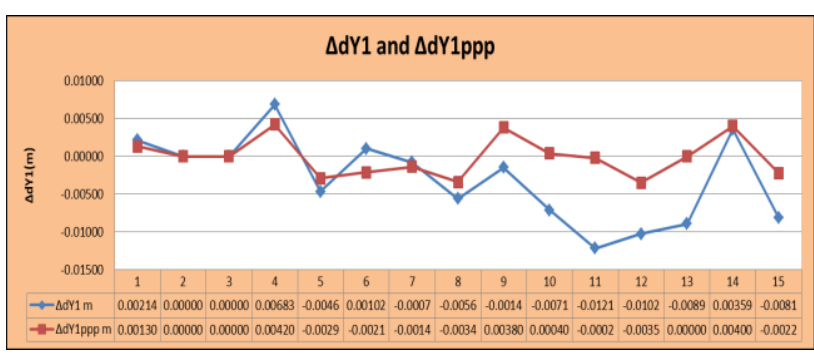

Figure13: Graph of the Difference Between $\Delta d Y 1 \&$ $\triangle$ dY1 PPP

Tables 25 and 26 also show the difference between the baseline displacements in the $\mathrm{Y}$ direction of the two cases. On the day of the earthquake, the values of $\Delta d Y$ differed from $\Delta d Y p p p$ about $1 \mathrm{~mm}$ to $3 \mathrm{~mm}$ at the baselines $1,4,5,6,7,8,9,10$, and 15 . Baseline $11 \mathrm{had}$ $1 \mathrm{~cm}$ as the displacement value of $\Delta \mathrm{dY}$ on the day of the earthquake, but in $\Delta \mathrm{dYppp}$ it was equal to $0.0002 \mathrm{~m}$. This means that these two points had no detected movement on the crust of the earth when the PPP solution was used but, with the use of the Bernese solution, the displacement value hit $1 \mathrm{~cm}$. that means that Bernese have accurate and logical results, which It is proportional to the earthquake shake and its impact on the earth's crust.

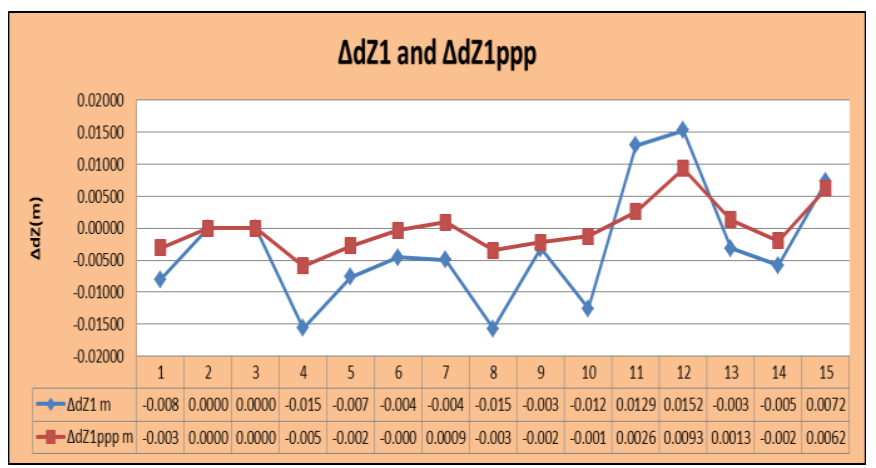

\section{Figure14: Graph of the Difference Between $\triangle d Z 1 \&$ $\triangle$ dZ1PPP}

The displacement values in the $\mathrm{Z}$ direction on the day of the earthquake were ranged from $3 \mathrm{~mm}$ to $1 \mathrm{~cm}$ in the Bernese solution, but their corresponding values in the PPP solution were from $1 \mathrm{~mm}$ to $6 \mathrm{~mm}$. Baseline BSHMNICO had the same displacement value in both solutions, that is, $1 \mathrm{~cm}$. Being one of the closest stations to the earthquake epicenter, station NICO had such an effect on displacement. On the day after a week of the earthquake, the values of the Bernese solution changed 
from $1 \mathrm{~mm}$ to $7 \mathrm{~mm}$. Yet, many baselines (e.g., ARUCANKR, ARUC-ISBA, \& MIKL-DYNG) had displacement values of $1 \mathrm{~cm}$. Baseline DYNG-RID had $9 \mathrm{~cm}$. However, in the PPP solution, these values changed from $1 \mathrm{~mm}$ to $8 \mathrm{~mm}$, except for the two baselines MAT1-MIKL and DYNG-MIKL that had the displacement value of $1 \mathrm{~cm}$.

\section{CONCLUSION}

This paper explains using the precise point positioning (PPP) technique to evaluate the precise coordinates for the network stations surrounding the epicenter of the Agean earthquake in turkey. Using The Canadian Geodetic Survey of Natural Resources, the CSRS-PPP service, then evaluates the network baselines horizontal displacements in the three directions $\mathrm{X}, \mathrm{Y}, \mathrm{Z}$, and the vertical displacements. By computing the station's height changes, and analyzing data using the time domain. That means evaluating all the requirements in three different periods, the first, on the day of occurrence of the Aegean earthquake, the second, before one week from the earthquake, and the third time on the day after one week from the earthquake. We compared the results displacement values from the PPP system and the results we have got before from data processing using the Bernese 5.2 program software. Our paper explains the different results between the two techniques for monitoring the response of the ground surface under the effect of the seismic shaking, and which technique gives us more observation accuracy. We found that the PPP technique gives the accurate results in the displacement of the point, but also we should repeat the processing for some points value to be ensured of our results accuracy and can depend on. Because any error when sending raw data of points, or an error in the user datum results in a large error in the results, so it is important to use a processing program that gives accurate results to ensure the displacements and results for each point. So we should be depending on the most accurate way to build an accurate database of point's displacements around any earthquake area in the world. To be as a reference guide can help the world soon to be an earthquake predicting tool. And try to make an early warning system to help countries for saving lives, properties and to reduce losses as possible.

\section{CrediT authorship contribution statement}

Elkutb: Methodology, Software, Review, Data Curation, Supervision.A.ElHattab: Conceptualization, Methodology, Review, Supervision, Writing -original Draft M.Rabah: Conceptualization, Formal Analysis, Review.Resource. A.Elkoshy: Review-editing, Supervision, Validation, Resource.

\section{Declaration of competing Interest}

The authors declare that they have no known competing financial interest or personal relationships that could have appeared to influence the work reported in this paper.

\section{References}

[1] https://webapp.geod.nrcan.gc.ca/geod/toolsoutils/ppp.php

[2] Dach, R., Lutz, S., Walser, P., \& Fridez, P. (2015). Bernese GNSS software version 5.2.

[3] Teferle, F. N., Orliac, E. J., \& Bingley, R. M. (2007). An assessment of Bernese GPS software precise point positioning using IGS final products for global site velocities. GPS solutions, 11(3), 205-213.

[4] Rui Tu, Fast determination of displacement by PPP velocity estimation, Geophysical Journal International, Volume 196, Issue 3, 1 March 2014, Pages 1397-1401, https://doi.org/10.1093/gji/ggt480

[5] Ehiorobo, Jacob, \& Ehigiator Irughe, Raphael. (2012). Evaluation of Absolute Displacement of Geodetic Control for Dam Deformation Monitoring Using CSRS-PPP Model. Journal of Earth Science and Engineering. 2. 277-286.

[6] "M 6.7 - 10km SSE of Bodrum, Turkey". United States Geological Survey. 21 July 2017. Retrieved 20 July 2017.

[7] Patricia A. Mothes, Frederique Rolandone, JeanMathieu Nocquet, Paul A. Jarrin, Alexandra P. Alvarado, Mario C. Ruiz, David Cisneros, Héctor Mora Páez, Mónica Segovia; Monitoring the Earthquake Cycle in the Northern Andes from the Ecuadorian GPS Network. Seismological Research Letters;89(2A):534541.doi: https://doi.org/10.1785/0220170243

[8] Chousianitis, K., \& Konca, A. O. ( 2018). Coseismic slip distribution of the 12 June $2017 \mathrm{M} \mathrm{w}=6.3$ Lesvos earthquake and imparted static stress changes to the neighboring crust. Journal of Geophysical Research: Solid Earth, 123, 8926- 8936. https://doi.org/10.1029/2018JB015950

[9] Dhanya, J., Maheshreddy Gade, and S. T. G. Raghukanth. (2017)"Ground motion estimation during artlthe 25th April 2015 Nepal earthquake." Acta Geodaetica et Geophysica 52.1 69-93. https://doi.org/10.1016/j.jafrearsci.2017.05.012. 